\title{
Ocorrência de Meloidogyne coffeicola em Cafeeiros do Município de Coromandel, Região do Alto Paranaíba em Minas Gerais
}

\author{
José M. C. Castro ${ }^{1}$, Vicente P. Campos $^{1}$ \& Marcos R. Dutra ${ }^{1}$ \\ 1'Departamento de Fitopatologia, UFLA, Cx. Postal 37, CEP 37200-000, Lavras, MG, e-mail: vpcampos@ufla.br
}

(Aceito para publicação em 16/12/2003)

Autor para correspondência: Vicente Paulo Campos

\begin{abstract}
Occurrence of Meloidogyne coffeicola in coffee plantations from Coromandel County in the region of Alto Paranaíba, Minas Gerais, Brazil

Coffee (Coffea arabica) plantations showing symptoms of decline, such as peeled and rough roots and fewer side rootlets were observed in the State of Minas Gerais, Brazil. Meloidogyne sp. females

were obtained from thicker roots, and processed for perineal patterns and $\alpha$-esterase electrophoresis analysis. It was concluded that $M$. coffeicola was the causal agent. The nematode incidence was occurring with field symptom patterns similar to those observed on coffee plantations of the State of Paraná, where most damage caused by $M$. coffeicola has been reported.
\end{abstract}

Em São Paulo e Paraná, Meloidogyne coffeicola Lordello \& Zamith tem sido encontrado causando sérios prejuízos à cafeicultura (Coffea arabica L.) [Campos, V.P. Café, Doenças causadas por nematóides. In: Ribeiro do Vale \& Zambolim (Eds.) Controle de Doenças de Plantas: Grandes Culturas, v.1, p.141, 1997]. Em Minas Gerais, foi encontrado em lavoura cafeeira do município de Machado (Guerra Neto, E.G. et al. Revista de Agricultura 58:45. 1983), a qual foi erradicada e não teve, até então, outra ocorrência desse nematóide no Estado.

Com apoio financeiro do PNP \& D/Café - EMBRAPA, tem sido feito levantamento de fitonematóides em cafezais de Minas Gerais. Recentemente, observaram-se plantas desfolhadas, com sistemas radiculares reduzidos, raízes mais grossas de superfície macia e lesões, com aspecto de cancro (Figura 1A), numa lavoura localizada em Coromandel que se apresentava definhada e improdutiva. Para diagnose, coletaram-se amostras de solo e raízes em torno de plantas doentes objetivando análise nematológica. Fêmeas de Meloidogyne sp. foram retiradas das raízes para exame da configuração perineal e extração de proteínas, as quais foram submetidas à análise de isoenzimas para a identificação da espécie pelo fenótipo de $\alpha$-esterase [Barker, K.R. et al. (Eds.) An advanced treatise on Meloidogyne, v. 2, 1985].

$\mathrm{O}$ formato alongado do corpo da fêmea e a existência de estrias entre o ânus e a vulva (Figura $1 \mathrm{~B}$ e C) indicaram tratar-se de M. coffeicola (Taylor, A.L., Sasser, J.N. Biology, identification and control of root-knot nematodes -Meloidogyne Species, 1978). A análise de $\alpha$-esterase revelou o fenótipo C2 (Figura 1D) (Carneiro, R.M.D.G et al. Nematology 2:645, 2000), confirmando a identificação da espécie.
Parte da lavoura atacada foi erradicada e outras medidas de controle devem ser implementadas no local.

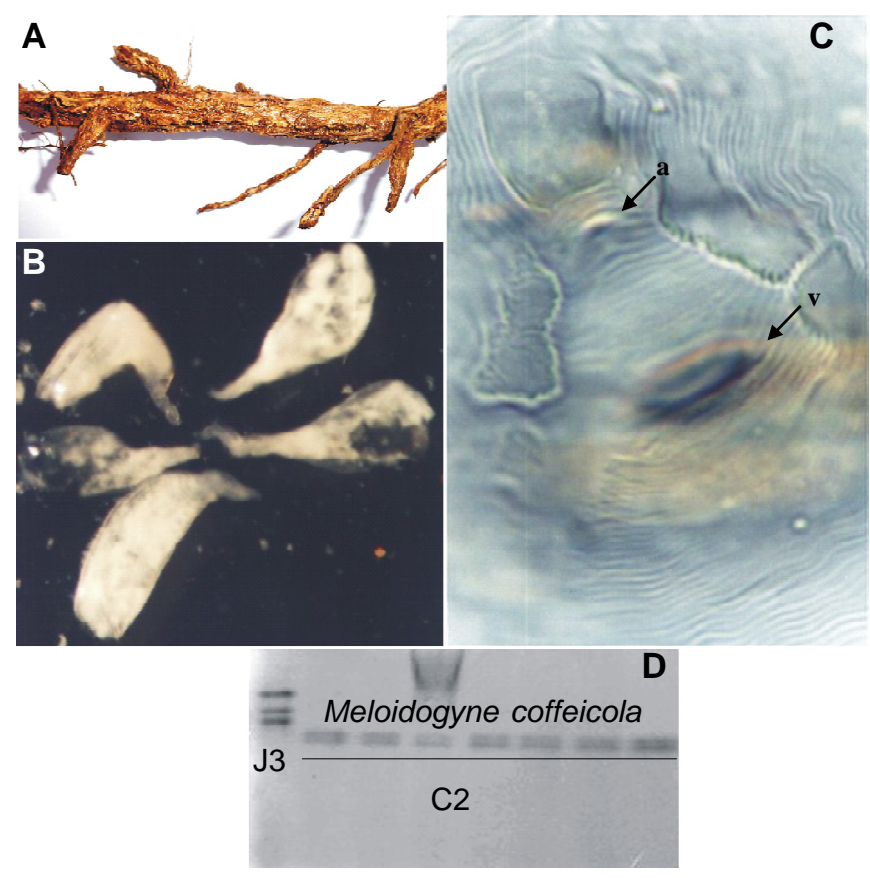

FIG. 1 - Sintomas do parasitismo de Meloidogyne coffeicola nas raízes de cafeeiro (Coffea arabica) (A). Fêmeas de M. coffeicola (B); Configuração perineal de $M$. coffeicola, a = ânus; v = vulva (C); Fenótipo de $\alpha$-esterase, C2, típico de $M$. coffeicola; fenótipo de $M$. javanica, J3, utilizado como padrão de comparação (D). 